\title{
Consumers' attitude toward Facebook advertising
}

\section{Fátima Ferreira}

University of Aveiro, Campus Universitário de Santiago, 3810-193 Aveiro, Portugal

Email: fatima.ferreira@ua.pt

\section{Belem Barbosa*}

GOVCOPP Research Unit and ISCA-UA Institute of Accounting and Administration, University of Aveiro, Rua Associação Humanitária dos Bombeiros Voluntários de Aveiro, 3810-500 Aveiro, Portugal

Email: belem.barbosa@ua.pt *Corresponding author

\begin{abstract}
This paper aims to provide a closer look at consumers' attitude toward Facebook advertising by providing a comparison between attitude toward brand posts and ads, a topic that has been disregarded in the extant literature. It also considers the relationship with the users' ad avoidance and electronic word-of-mouth communication. An exploratory quantitative analysis was performed by means of a structured self-administered questionnaire. 385 individuals aged between 18 and 44 participated in the study. The results include evidence on respondents' more favourable attitude toward brand posts than toward Facebook ads. Moreover, ads are considered more annoying by those who spend more time on Facebook. These results help shed the light on how Facebook users handle ads and brand posts, offering some clues for a more effective social media marketing strategy.
\end{abstract}

Keywords: attitude toward advertising; SNS advertising; Facebook advertising; ad avoidance; electronic word-of-mouth communication.

Reference to this paper should be made as follows: Ferreira, F. and Barbosa, B. (2017) 'Consumers' attitude toward Facebook advertising', Int. J. Electronic Marketing and Retailing, Vol. 8, No. 1, pp.45-57.

Biographical notes: Fátima Ferreira received her MSc in Marketing from the University of Aveiro. She works as a Technical Assistant at the University of Aveiro. Her major interests are organisational communication, social network management, sensory marketing and consumer behaviour.

Belem Barbosa is an Invited Adjunct Professor at the University of Aveiro and a member of GOVCOPP, the research unit on Governance, Competitiveness and Public Policy. She received her PhD in Business and Management Studies - specialisation in Marketing and Strategy from the University of Porto, Portugal. Her research interests lie primarily in the area of consumer behaviour, including word-of-mouth communication, internet marketing and sustainability marketing. 


\section{Introduction}

The social network sites (SNS) are increasingly present in the daily lives of consumers, both as a source of information and as a mean of entertainment and peer interaction. For this reason the SNS are increasingly becoming an important communication tool for businesses (Boyd and Ellison, 2007; Qualman, 2012; Tuten, 2008), for promoting brands and interacting with customers and prospects (Boyd and Ellison, 2007; Curran et al., 2011; Hassan et al., 2013; Vries et al., 2012). The SNS are credited with the ability to increase brand awareness and attract new customers (Tuten, 2008).

Amongst SNS, Facebook is one of the most attractive for both users and marketers. Besides its popularity, Facebook has specificities in the brand-consumer dynamic that makes it different from the other media and requires specific marketing approaches, as stated by Hodis et al. (2015). The social media marketing activities in Facebook include creating brand pages, posting content and doing advertising. Brand posts are content in the form of text, image, video and links created and posted by the brand page managers, that will be embed in followers' news feed and are a central element of social media marketing in Facebook, with a lot of attention placed at their ability to generate interaction with followers. The number of likes is an accepted indicator of content effectiveness, as the more likes a post generates the more attention it receives, resulting in increased exposure (Brettel et al., 2015). However, post reach depends also on its promotion. The increased use of advertising on Facebook is a result of the increased volume of content shared and of recent changes into Facebook's news feed algorithm which led to a pronounced decrease in the organic reach. Advertising on Facebook is increasingly used by companies to enhance post reach and has become an essential tactic to leverage the news feed visibility. Still, it is known that consumers tend to form negative attitudes toward advertising (Li et al., 2002; Speck and Elliott, 1997; Wang et al., 2002) leading them to ignore it and avoid it. Thus, the adoption of a SNS strategy depends on understanding the consumers' behaviour on these platforms, namely their attitude toward ads and brand posts. Although previous studies have investigated advertising avoidance in traditional media and on the internet there has been little research on advertising on SNS (Hodis et al., 2015; Kelly et al., 2010; Yaakop et al., 2013, Zeng et al., 2010). Therefore, this paper aims to contribute to the understanding of consumers' attitude towards advertising on Facebook, as well as toward brands' posts, looking for directions for the definition of effective social media marketing strategies. To the best of our knowledge, this is the first attempt to analyse and compare attitude towards brands' ads and posts on Facebook. Hence, we provide empirical evidence of differences in those attitudes, being less favourable towards Facebook ads. The results emphasize the relevance of the informative and entertainment characteristics to foster brand content shares and reach. As such, this paper provides empirical contributions that help delineate more effective social media marketing strategies. On the following pages are compiled literature contributions which support the research hypotheses defined for this work. Also featured are the results of a quantitative and exploratory study, which had the participation of 385 Facebook users aged between 18 and 44 . 


\section{Literature review}

Attitudes are learned predispositions to respond to an object or class of objects in a consistently favourable or unfavourable way (Assael, 1992; Bohner and Dickel, 2011; Eagly and Ghaiken, 2007; Kotler and Armstrong, 2006; Schwarz, 2007; Solomon et al., 2012). Consumers' attitudes are accepted as a key element of their behaviour. A recurring theme in literature is the attitude towards advertising, which helps to understand how consumers deal with this frequently used marketing tool. Advertising is an important social phenomenon that stimulates consumption and the economic activity and also models lifestyles (Belch and Belch, 2008; Pollya and Mittai, 1993). The importance of advertising as a promotion tool depends on its ability to lead consumers not only to buy but also to develop brand loyalty (Eze and Lee, 2012). Consumers' attitude towards advertising is considered an important indicator to measure its effectiveness (Wang and Sun, 2010).

The perceived value of advertising leads individuals to develop pleasant opinions or condemnations of the various aspects of advertising. Advertising can generate high levels of distrust and discredit of the information presented (Ducoffe and Curlo, 2000; Pollya and Mittai, 1993), leading consumers to form negative attitudes not only towards advertising, but also toward the advertised brand or product (Ducoffe, 1996). Consumers evaluate advertising based on three factors: informativeness, irritation and entertainment (Ducoffe, 1995). Through its informative content, advertising delivers information about the organisations and the products and services they offer (Alwitt and Prabhaker, 1992; Hassan et al., 2013). The informativeness in advertising keeps consumers up-to-date and the information is used when needed, namely at the time of the purchase decision. Consumers will have more favourable attitudinal reactions towards the ads that they find more valuable (Ducoffe, 1995, 1996). The informativeness component is the main reason why consumers pay attention to the ads and it positively affects the advertising value. The entertainment component is also positively related to consumer attitude towards advertising (Ducoffe, 1996; Hassan et al., 2013; Schlosser et al., 1999). The entertainment content in advertising arouses interest (Wang and Sun, 2010), thus the ads with higher visual and entertainment complexity tend to generate a more positive attitude in individuals and may also positively influence their buying behaviour toward the advertised brand or product (Ducoffe, 1995; Jin and Villegas, 2007). On the other hand, consumer irritation towards advertising is a result of the ads being perceived as offensive and not informative (Alwitt and Prabhaker, 1992, 1994; Ducoffe, 1995), annoying (Ducoffe, 1995, 1996; Hassan et al., 2013) or evasive (Taylor et al., 2011). Advertising is usually deemed intrusive as it interrupts the action currently being performed creating irritation. Irritation reduces the effectiveness of advertising content and tends to generate a negative attitude towards the ad (Ducoffe, 1995). Consumers' attitudes toward brand posts determine their overall brand evaluations and their attitudes toward the brand (Chen et al., 2015).

The literature suggests that consumers consider advertising on the internet less irritating and more acceptable than advertising in traditional media (Zhou, 2002). Advertising in traditional media is unidirectional (Heeter, 2010; Karimova, 2011; Tuten, 2008) and lacks interactivity, since consumers are passively exposed to product information (Bezjian-Avery and Calder, 1998; Hoffman and Novak, 1996; Pavlou and Stewart, 2010). On the other hand, not only online users have an overall control of what they want to access, receive, but also they create and share information (Akar and Topçu, 
2011; Hoffman and Novak, 1996; Liu and Shrum, 2002; Pavlou and Stewart, 2010; Schlosser et al., 1999; Tuten, 2008; Wolin et al., 2002). The interactivity of the online media is the degree to which two or more communication parties can act on each other and is perceived by them as bidirectional, mutually controllable (Karimova, 2011; Liu and Shrum, 2002; Yadav and Varadarajan, 2005), timely and responsive (Yadav and Varadajan, 2005). The interactivity of the internet advertising increases the potential enjoyment experienced and consequently contributes to form more positive attitudes (Bevan-Dye, 2013).

With SNS like Facebook, brands can create their own content and disseminate it, as well as advertise. Facebook ads are always present, given that when a user tries to close or minimise one ad, another ad will appear in the place of the one that has been discarded (Curran et al., 2011). In fact, the elimination of Facebook ads is only possible by using a blocking application, which is an offbeat practice among Facebook users. Curran et al. (2011) stress that the ads are more easily accepted by consumers that do not perceive they are being targeted by a campaign. Therefore, attitude towards brand posts is expected to be less negative as compared to advertising. Consequently, it was defined as a research hypothesis:

H1 Consumers' attitude toward brand posts is significantly more favourable than their attitude toward Facebook advertising.

\subsection{Factors influencing attitude towards advertising}

The literature highlights several factors that influence attitude towards advertising. Several studies suggest that males have a more favourable attitude towards advertising than females (e.g., Shavitt et al., 1998; Wolin and Korgaonkar, 2003). Accordingly, the following research hypothesis was postulated:

H2 Males have a more favourable attitude towards Facebook advertising compared to Females.

It is also common to identify a negative correlation between age and attitude towards advertising in different media such as newspapers (e.g., Speck and Elliott, 1997), television (e.g., Alwitt and Prabhaker, 1994; Shavitt et al., 1998) and the internet (e.g., Wolin et al., 2002). In line with these results, the following research hypothesis has been defined:

H3 Attitude toward Facebook advertising is negatively associated with the consumers' age.

Previous studies indicate that individuals with lower levels of schooling show a more favourable attitude towards advertising presented in the various media (e.g., Alwitt and Prabhaker, 1994; Shavitt et al., 1998; Wolin et al., 2002). Based on these results, the following research hypothesis has been stated:

H4 Attitude toward Facebook advertising is negatively associated with the consumers' level of education. 
A similar relationship has been identified between the income level and attitude toward advertising on television (e.g., Alwitt and Prabhaker, 1994; Shavitt et al., 1998) and on the internet (Wolin et al., 2002). Thus, the following research hypothesis has been defined:

H5 Attitude toward Facebook advertising is negatively associated with the consumers' income.

Other factors were identified as influencers of consumer attitudes towards online advertising, such as the time that users spend on the internet. There is evidence that the greater the amount of time that users spend on the internet, the less positive are their attitudes toward advertising (Yang, 2003). This is due to the fact that these users perceive internet advertising as a constant intrusion (Yang, 2003). Accordingly, the following research hypothesis was postulated:

H6 Attitude toward Facebook advertising is negatively associated with the amount of time the consumer spends on the social network.

\subsection{Relationship with electronic word-of-mouth communication}

Due to their interactive features, Web 2.0 and particularly social media consist of multi-directional dialogues: brands speak to customers, customers talk to brands and, most importantly, customers talk to each other (Akar and Topçu, 2011). Hennig-Thurau et al. (2004, p.39) define electronic word-of-mouth communication "as any positive or negative statement made by potential, actual, or former customers about a product or company, which is made available to a multitude of people and institutions via the internet". Electronic word-of-mouth communication includes sharing positive or negative feedback about a product or organisation and gives consumers the power to quickly and voluntary convey that information to thousands of other users they are connected to in the SNS (Mangold and Faulds, 2009; Wang et al., 2013). Whenever brands provide information about their products, they provide content that consumers can incorporate into their conversations (e.g., Curran et al., 2011; Smith et al., 2012). Consumers can share and interact with content produced by the brands, which, because of the consumer's actions, will become visible to the other members of his network. The interaction among users is described as an important social force which directly influences all aspects of consumer behaviour, from the acquisition of information (Duan et al., 2008; Mangold and Faulds, 2009) to the purchasing behaviour (Chen and Xie, 2008; Dehghani and Tumer, 2015; Kozinets et al., 2010). Accordingly, the attitude toward Facebook advertising is expected to be positively associated to consumers' likelihood to produce and share branded content with their SNS connections (Chu and Kim, 2011). And so the following research hypothesis has been formulated:

H7 There is a positive association between users' electronic word-of-mouth communication and attitude toward Facebook advertising.

\subsection{Ad avoidance}

Several studies refer that individuals tend to have negative attitudes towards advertising across all media, whether print or electronic (Li et al., 2002; Speck and Elliott, 1997), with SNS such as Facebook (Celebi, 2015). The negative attitude leads to ad avoidance 
behaviour (Jin and Villegas, 2007; Rojas-Méndez et al., 2009; Speck and Elliott, 1997). Consumers' ad avoidance strategies encompass all actions the users may take to reduce their exposure to the ad content (Speck and Elliott, 1997), such as performing other tasks during the advertisement, leave the location or site, scroll or close the pop-up windows (Cho and Cheon, 2004; Speck and Elliott, 1997). Thus, the following research hypothesis has been defined:

H8 There is a negative association between the consumers' attitude towards Facebook advertising and their ad avoidance.

\section{Method}

To test the research hypotheses an exploratory quantitative approach was adopted, in the form of a self-administered questionnaire. A total of 385 Portuguese Facebook users aged 18 to 44 participated in the study. By the time the survey was performed, this age group accounted for $70 \%$ of Portuguese Facebook users (Socialbakers, 2014). The sample consisted of 188 males (48.8\%) and 197 females (51.2\%). According to Marktest (2014) and Socialbakers (2014) the percentage of Portuguese male and female Facebook users is similar. $80 \%$ of respondents access Facebook daily, a figure that is consistent with the results of a Netsonda's (2011) study according to which $80 \%$ of Portuguese Facebook users are always connected to Facebook or accessing it at least once a day.

The questionnaire comprised questions about Facebook use frequency, the attitude towards Facebook posts and ads and the respondents' ad avoidance and word-of-mouth communication practices on Facebook. In addition, information was collected on the socio-demographic characterisation of the respondents (gender, age, income and educational level background) and the amount of time the respondents spend on Facebook.

\subsection{Measures}

This study adapted several scales developed by other authors. The consumers' attitude toward brand posts and toward Facebook advertising was adapted from Cheng et al. (2009). The scale comprises three dimensions and a total of 16 items, ranging from 1 (strongly disagree) to 5 (strongly agree). The ad avoidance was measured using Cho and Cheon's (2004) scale with 18 items and three dimensions, with answers ranging between 1 (strongly disagree) and 7 (strongly agree). The electronic word-of-mouth scale was adapted from Chu and Kim (2011), comprising nine items organised in three dimensions, with answers ranging from 1 (strongly disagree) to 7 (strongly agree).

\section{Results}

The Cronbach's alpha coefficients were computed for the various dimensions of the scales used in this study, to assess their internal consistency. All the alpha values, ranging from .849 to .947 indicate good reliability (Table 1). The assumptions of independence of samples and normality distribution were also verified, having been assumed the central limit theorem for the use of parametric tests. 
Table 1 Cronbach's alpha coefficients

\begin{tabular}{lc}
\hline Constructs & Cronbarch's alpha coefficients \\
\hline Advertising - informative (six items) & .863 \\
Advertising - entertainment (five items) & .849 \\
Advertising - irritation (five items) & .897 \\
Brand posts - informative (six items) & .891 \\
Brand posts - entertainment (five items) & .869 \\
Brand posts - irritation (five items) & .919 \\
Cognitive ad avoidance (eight items) & .947 \\
Affective ad avoidance (six items) & .938 \\
Behavioural ad avoidance (four items) & .853 \\
WOM - opinion seeking (three items) & .941 \\
WOM - opinion giving (three items) & .915 \\
WOM - opinion passing (three items) & .915 \\
\hline
\end{tabular}

The results of the independent sample t-test show that the regularity of Facebook access between men and women is similar $\left(M_{\text {men }}=6.28, S D=1.039 ; M_{\text {women }}=6.24\right.$, $S D=1.031), t(383)=0.363, p=0.717)$. This result is consistent with the Netsonda's (2012) study which revealed that men and women connect to Facebook with similar regularity.

Attitude towards Facebook advertising differs significantly between men and women, whether in the informational dimension $\left(M_{\mathrm{men}}=3.211, S D=0.802 ; M_{\text {women }}=3.507\right.$, $S D=0.629), t(383)=-4.045, p=0.000$, in the entertainment dimension $\left(M_{\text {men }}=2.285\right.$, $\left.S D=0.825 ; M_{\text {women }}=2.591, S D=0.730\right), t(383)=-3.867, p=0.000$, or in the irritation dimension $\left(M_{\text {men }}=3.320, S D=0.872 ; M_{\text {women }}=3.113, S D=0.770\right), t(383)=2.464$, $p=0.014$. Female respondents hold a more favourable attitude toward Facebook advertising than male respondents. Consequently, the research hypothesis $\mathrm{H} 2$ is not supported.

Spearman's rho was used to determine the correlations between attitude towards Facebook advertising and the users' age, qualifications, income and regularity of access to Facebook. The correlation between users' age and the irritation dimension is negative and weak $r(384)=-0.266, p=0.00$, indicating that older people do not seem to consider advertising as annoying as younger people. As for the informativeness $r(384)=-0.035$, $\mathrm{p}=0.246$ and entertainment dimensions $r(384=-0.118, \mathrm{p}=0.011)$ no correlation between the variables was found. Hence, the results do not support the research hypothesis $\mathrm{H} 3$.

Taking into account the users' qualifications, no correlation was found with attitude toward Facebook advertising, whether in the information dimension $r(382)=-0.034$, $p=0.253$, entertainment dimension $r(382)=-0.009 p=0.433$, or irritation dimension $r(382)=-0.062, p=0.112)$. Hence, this study does not support the research hypothesis H4.

The correlation between users' annual income and the entertainment dimension is negative and weak $r(344)=-0.223, p=0.000$. No correlation was found with the informativeness $r(344)=-0.116, p=0.016$, or irritation $r(344)=0.003, p=0.479$ dimensions. Therefore, the research hypothesis H5 is partially supported by this study. 
By analysing the regularity of the users' access to Facebook, a weak positive correlation was found between with the irritation dimension $r(385)=0.211, p=0.003$ whereas no correlation was found with the informativeness and entertainment dimensions $(r(385)=0.140, p=0.003$ and $r(385)=0.184, p=0.000$, respectively). So, no empirical support is provided for the research hypothesis H6.

\subsection{Attitude toward Facebook advertising vs. attitude toward brand posts on Facebook}

The paired sample t-test indicated that consumers have a more favourable attitude toward the brands posts as compared to ads, considering the informativeness dimension $\left(M_{\text {posts }}=3.493, S D=0.708 ; M_{\text {adverts }}=3.362, S D=0.733\right), t(384)=-3.941, p=0.000$, the entertainment dimension $\left(M_{\text {posts }}=2.644, S D=0.837 ; M_{\text {adverts }}=2.442, S D=0.792\right)$, $t(384)=-6.446, p=0.000$ and the irritation dimension $\left(M_{\text {posts }}=2.881, S D=0.868\right)$, $\left(M_{\text {adverts }}=3.214, S D=0.827\right), t(384)=8.815, p=0.000$. Therefore, the present study provides empirical support for the research hypothesis H1.

\subsection{Attitude toward Facebook advertising vs. electronic word-of-mouth communication}

As one of the hypotheses under study $(\mathrm{H} 7)$ pertains to the relationship between electronic word-of-mouth communication and attitude toward advertising, the Spearman's rho between the dimensions of the two variables was calculated. A weak positive correlation was found between attitude toward Facebook advertising informativeness dimension and the three dimensions of electronic word-of-mouth communication: opinion seeking, $r(385)=0.274, p=0.000$, opinion giving $r(385)=0.276, p=0.000$ and opinion passing $r(385)=0.341, p=0.000$. The same applies to the entertainment dimension, which showed weak and positive correlations with opinion seeking $r(385)=0.392, p=0.000$, opinion passing $r(385)=0.369, p=0.000$ and opinion giving $r(385)=0.389, p=0.000$. However, no correlation was found between attitude toward Facebook advertising's irritation dimension and the three dimensions of electronic word-of-mouth communication: opinion seeking $r(385)=-0.070, p=0.086$, opinion giving $r(385)=-0.098, p=0.027$ and opinion passing $r(385)=-0.196, p=0.000$. Thus, this study provides partial empirical support for the research hypothesis $\mathrm{H} 7$.

\subsection{Ad avoidance vs. attitude toward Facebook advertising}

As presented in the literature review section, several contributions lead us to hypothesize a negative association between attitude toward Facebook advertising and ad avoidance, which is supported by the data of this study, tested with Spearman's rho correlations. The informativeness dimension of attitude toward Facebook advertising has a moderate negative correlation with the cognitive ad avoidance $r(385)=-0.402, p=0.000$ and with the affective ad avoidance dimension $r(385)=-0.421, p=0.000$ and a weak negative correlation with the behavioural ad avoidance dimension $r(385)=-0.294, p=0.000$. The entertainment dimension of attitude toward Facebook advertising has a weak negative correlation with the cognitive ad avoidance $r(385)=-0.336, p=0.000$, affective ad avoidance $r(385)=-0.275, p=0.000$ and behavioural ad avoidance $r(385)=-0.183$, $p=0.000$ dimensions. The irritation dimension of attitude toward Facebook advertising 
has a moderate positive correlation with all dimensions of ad avoidance: cognitive $r(385)=0.422, p=0.000$ affective $r(385)=0.492, p=0.000$ and behavioural $r(385)=0.404, p=0.000$.

\section{Conclusions}

In recent years brands are experiencing far lower visibility of their posts on the news feed of their Facebook followers, due to not only to the increased amount of content published by brands and users, but also to the presence of mechanisms implemented by Facebook to rank and select the posts displayed on each person's news feed. It is therefore increasingly important to adopt strategies that maximise organic reach in order to increase marketing effectiveness in SNS. Although Facebook's optimisation tools enable publishers to target those more likely of being interested in a specific post, it does not guarantee that all targeted followers will see it. The reach of a post is maximised but Facebook's optimisation tools do not replace the range achieved by advertising. Consequently, an effective Facebook strategy is necessarily twofold, combining content posts with advertising actions and thus maximising the return on investment. Being that the use of Facebook advertising is unavoidable, whether in the form of adverts or promoted posts, our study points to a greater effectiveness of posts that appear in the news feed when compared to ads, since attitude toward advertising is more negative than toward brand posts for all the three dimensions considered: informativeness, entertainment and irritation. This result is in agreement with the conclusions by Curran et al. (2011), who claim that marketing strategies work better when customers do not know they are being targeted. In addition and as reported by Yaakop et al. (2013), we found a negative association between attitude toward advertising and ad avoidance. The results of this study also include empirical evidence of a positive association between the informativeness and entertainment dimensions of the attitude toward Facebook advertising and electronic word-of-mouth communication. The participants in this study with a more positive attitude toward Facebook advertising are also the most likely to send electronic word-of-mouth communication and the less likely to avoid ads. Hence, these users are the most suitable targets for advertising campaigns on social networks.

\subsection{Management implications}

The demographic characteristics are one of the main criteria to define target segments, in particular as regards to advertising. Hodis et al. (2015) stress that Facebook has become an ideal platform for segmenting and targeting ads according to users' demographic information but its efficacy is disappointing. Accordingly, our study shows that these characteristics are not good predictors of the attitude toward advertising given that most assumptions relating to this matter were not supported. Two conclusions can be drawn from these results: on one hand, the need to further explore the relationship between attitude toward Facebook advertising and sociodemographic factors and, on the other the need to develop alternative criteria for segmentation and targeting, including targeting individuals who are more likely to pay attention and react positively when viewing organic or sponsored brand posts. As mentioned by Schlosser et al. (1999), demographic characteristics alone cannot explain the nature of attitudes towards advertising, so these criteria are not enough to ensure social media campaigns' effectiveness. 
According to the results of this study, the users who spend more time on Facebook are the ones finding Facebook advertising more annoying. These users are more exposed and have increased opportunities for interaction with branded content, but this increased exposure is associated with a more negative attitude toward Facebook advertising and with a lower propensity to interact with the ads, including passing word-of-mouth communication to other consumers. Similar evidence was reported by Yang (2003), who found that the more time users spent on the internet the less positive their attitudes toward internet advertising would be. Considering the need to leverage posts' visibility with advertising, it is recommended the adoption of more sophisticated targeting techniques, in order to increase the effectiveness of the ad. Moreover, social media campaigns should invest in creative and innovative content and focus on creating value for social network users, namely enhancing the informative and entertainment components of ads.

\subsection{Limitations and suggestions for future research}

The issue addressed in this study is still unexplored and the results provide interesting clues to the definition social media marketing strategies. Hence, we recommend that future studies continue to examine attitudes toward advertising on Facebook and on other SNS, in order to produce a body of empirical contributions that enables more robust conclusions and the validation of the provided results. Since users' interaction, by clicking, commenting or sharing, is critical to the success of social media campaigns, the fact that the most frequent Facebook users are those who are the most irritated by advertising raises a red flag to all professionals working on this SNS. Therefore, this topic should be further explored in future research. One relevant perspective is the reactions to specific content design options, which are expected to vary across consumers' characteristics. Another research opportunity lies in the comparison of results in other social networks, in particular those alternative to microblogging. Future studies may also test more sophisticated segmentation criteria such as lifestyle, or types of use of social networks.

It is also recommended that future studies explore the relationship between attitude toward advertising and types of user interaction. Considering the managers' need to monitor the effectiveness of participation, it will be important to verify the relationship between attitude toward advertising and the propensity to like, comment and share, assessing whether this propensity varies with the characteristics of the users themselves.

Finally, this study addresses attitude toward Facebook advertising in general, not limited to a specific brand or product. In future studies it will be appropriate to examine particular cases, such as business-to-business brands, public and private consumption products, luxury products, new products and brands, or non-profit institutions, in order to further contributing to the effectiveness of brands' social media marketing strategy.

\section{References}

Akar, E. and Topçu, B. (2011) 'An examination of the factors influencing consumers' attitudes toward social media marketing', Journal of Internet Commerce, Vol. 10, No. 1, pp.35-67.

Alwitt, L.F. and Prabhaker, P.R. (1992) 'Functional and belief dimensions of attitudes to television advertising: implications for copytesting', Journal of Advertising Research, September/October, Vol. 32, No. 5, pp.30-42. 
Alwitt, L.F. and Prabhaker, P.R. (1994) 'Identifying who dislikes television advertising: not by demographics alone', Journal of Advertising Research, Vol. 34, No. 6, pp.1-16.

Assael, H. (1992) Consumer Behavior and Marketing Action, 4th ed., PWS-Kent Publishing Company, Boston.

Belch, G.E. and Belch, M.A. (2008) Advertising and Promotion: An Integrated Marketing Communications Perspective, 6th ed., McGraw-Hill, Boston.

Bevan-Dye, A.L. (2013) 'Black generation y students' attitudes towards web advertising value', Mediterranean Journal of Social Sciences, Vol. 4, No. 2, pp.155-164.

Bezjian-Avery, A. and Calder, B. (1998) 'New media interactive advertising vs. traditional advertising', Journal of Advertising Research, July/August, Vol. 38, No. 4, pp.23-32.

Bohner, G. and Dickel, N. (2011) 'Attitudes and attitude change', Annual Review of Psychology, Vol. 62, pp.391-417.

Boyd, D.M. and Ellison, N.B. (2007) 'Social network sites: definition, history and scholarship', Journal of Computer-Mediated Communication, Vol. 13, No. 1, pp.210-230.

Brettel, M., Reich, J-C., Gavilanes, J.M. and Flatten, T.C. (2015) 'What drives advertising success on Facebook? An advertising-effectiveness model measuring the effects on sales of 'likes' and other social-network stimuli', Journal of Advertising Research, Vol. 55, No. 2, pp.162-175.

Celebi, S.I. (2015) 'How do motives affect attitudes and behaviors toward internet advertising and Facebook advertising?', Computers in Human Behavior, Vol. 51, Part A, pp.312-324.

Chen, K-J., Kim, J. and Lin, J-S. (2015) 'The effects of affective and cognitive elaborations from Facebook posts on consumer attitude formation', Journal of Consumer Behaviour, Vol. 14, No. 3, pp.208-218.

Chen, Y. and Xie, J. (2008) 'Online consumer review: word-of-mouth as a new element of marketing communication mix', Management Science, Vol. 5, No. 3, pp.477-491.

Cheng, J.M., Blankson, C., Wang, E. and Chen, L. (2009) 'Consumer attitudes and interactive digital advertising', International Journal of Advertising, Vol. 28, No. 3, pp.501-525.

Cho, C. and Cheon, H.J. (2004) 'Why do people avoid advertising on the internet?', Journal of Advertising, Vol. 33, No. 4, pp.89-97.

Chu, S. and Kim, Y. (2011) 'Determinants of consumer engagement in electronic word-of-mouth (eWOM) in social networking sites', International Journal of Advertising, Vol. 30, No. 1, pp.47-75.

Curran, K., Grahan, S. and Temple, C. (2011) 'Advertising on Facebook', International Journal of E-Business Development, Vol. 1, No. 1, pp.26-33.

Dehghani, M. and Tumer, M. (2015) 'A research on effectiveness of Facebook advertising on enhancing purchase intention of consumers', Computers in Human Behavior, Vol. 49, pp.597-600.

Duan, W., Gu, B. and Whinston, A.B. (2008) 'Do online reviews matter? - an empirical investigation of panel data', Decision Support Systems, Vol. 45, No. 4, pp.1007-1016.

Ducoffe, R. (1995) 'How consumers assess the value of advertising', Journal of Current Issues and Research in Advertising, Vol. 17, No. 1, pp.2-18.

Ducoffe, R. (1996) 'Advertising value and advertising on the web', Journal of Advertising Research, Vol. 36, No. 5, pp.21-35.

Ducoffe, R. and Curlo, E. (2000) 'Advertising value and advertising processing', Journal of Marketing Communications, Vol. 6, No. 4, pp.247-262.

Eagly, A.H. and Ghaiken, S. (2007) 'The advantages of an inclusive definition of attitude', Social Cognition, Vol. 25, No. 5, pp.582-602.

Eze, U.C. and Lee, C.H. (2012) 'Consumers' attitude towards advertising', International Journal of Business and Management, Vol. 7, No. 13, pp.94-108. 
Hassan, M.U., Fatima, S., Akram, A., Abbas, J. and Hasnain, A. (2013) 'Determinants of consumer attitude towards social-networking sites advertisement: testing the mediating role of advertising value', Middle-East Journal of Scientific Research, Vol. 16, No. 3, pp.319-330.

Heeter, C. (2010) 'Interactivity in the context of designed experiences', Journal of Interactive Advertising, Vol. 1, No. 1, pp.34-15.

Hennig-Thurau, T., Gwinner, K., Walsh, G. and Gremler, D. (2004) 'Electronic word-of-mouth via consumer-opinion platforms: what motivates consumers to articulate themselves on the internet?', Journal of Interactive Marketing, Vol. 18, No. 1, pp.38-52.

Hodis, M.A., Sriramachandramurthy, R. and Sashittal, H.C. (2015) 'Interact with me on my terms: a four segment Facebook engagement framework for marketers', Journal of Marketing Management, Vol. 31, Nos. 11-12, pp.1255-1284.

Hoffman, D.L. and Novak, T.P. (1996) 'Marketing in hypermedia computer-mediated environments conceptual foundations', Journal of Marketing, Vol. 60, No. 3, pp.50-68.

Jin, C.H. and Villegas, J. (2007) 'Consumer responses to advertising on the internet: the effect of individual difference on ambivalence and avoidance', Cyberpsychology \& Behavior: The Impact of the Internet, Multimedia and Virtual Reality on Behavior and Society, Vol. 10, No. 2, pp.258-266.

Karimova, G.Z. (2011) 'Interactivity and advertising communication', Journal of Media and Communication Studies, Vol. 3, No. 5, pp.160-169.

Kelly, L., Kerr, G. and Drennan, J. (2010) 'Avoidance of advertising in social networking sites: the teenage perspective', Journal of Interactive Advertising, Vol. 10, No. 2, pp.16-27.

Kotler, P. and Armstrong, G. (2006) Principles of Marketing, 15th ed., Pearson, New Jersey.

Kozinets, R.V., Valck, K., Wojnicki, A.C. and Wilner, S.J.S. (2010) 'Networked narratives: understanding word-of-mouth', Journal of Marketing, Vol. 74, No. 2, pp.71-89.

Li, H., Edwards, S.M. and Lee, J.H. (2002) 'Measuring the intrusiveness of advertisements: scale development and validation', Journal of Advertising, Vol. 31, No. 2, pp.37-47.

Liu, Y. and Shrum, L.J. (2002) 'What is interactivity and is it always such a good thing? implications of definition, person and situation for the influence of interactivity on advertising effectiveness', Journal of Advertising, Vol. 31, No. 4, pp.53-64.

Mangold, W.G. and Faulds, D.J. (2009) 'Social media: the new hybrid element of the promotion mix', Business Horizons, Vol. 52, No. 4, pp.357-365.

Marktest (2014) Os Portugueses e as Redes Sociais 2014 [online] http://www.marktest.com/ wap/private/images/logos/Folheto_redes_sociais_2014.pdf (accessed 21 July 2015).

Netsonda (2011) Face to Facebook 2011 [online] http://www.netsonda.pt/not_noticias_detail.php? aID $=1693$ (accessed 21 July 2015).

Netsonda (2012) Face to Facebook 2012 [online] http://www.netsonda.pt/xms/files/Downloads/ Netsonda_FaceToFacebook_Outubro2012.pdf (accessed 21 July 2015).

Pavlou, P.A. and Stewart, D.W. (2010) 'Measuring the effects and effectiveness of interactive advertising: a research agenda', Journal of Interactive Advertising, Vol. 1, No. 1, pp.62-78.

Pollya, R.W. and Mittai, B. 'Here's the beef: factors, determinants and segments in consumer criticism of advertising', Journal of Marketing, Vol. 57, No. 3, pp.99-114.

Qualman, E. (2012) Socialnomics: How Social Media Transforms the Way We Live and do Business, 2nd ed., John Wiley \& Sons, New Jersey.

Rojas-Méndez, J.I., Davies, G. and Madran, C. (2009) 'Universal differences in advertising avoidance behavior: a cross-cultural study', Journal of Business Research, Vol. 62, No. 10, pp.947-954.

Schlosser, A.E., Shavitt, S. and Kanfer, A. (1999) 'Survey of internet users' attitudes toward internet advertisin', Journal of Interactive Marketing, Vol. 13, No. 3, pp.34-54.

Schwarz, N. (2007) 'Attitude construction: evaluation in context', Social Cognition, Vol. 25, No. 5, pp.638-656. 
Shavitt, S., Lowewy, P. and Haefner, J. (1998) 'Public attitudes toward advertising: more favorable than you might think', Journal of Advertising Research, Vol. 38, No. 4, pp.7-22.

Smith, A.N., Fischer, E. and Yongjian, C. (2012) 'How does brand-related user-generated content differ across Youtube, Facebook and Twitter?', Journal of Interactive Marketing, Vol. 26, No. 2, pp.102-113.

Socialbakers (2014) Portugal Facebook Statistics 2014 [online] http://www.socialbakers.com/ facebook-statistics/portugal (accessed 15 February 2014).

Solomon, M., Russell-Bennett, R. and Previte, J. (2012) Consumer Behaviour, 4th ed., Pearson Higher Education, Europe.

Speck, P.S. and Elliott, M.T. (1997) 'Predictors of advertising avoidance in print and broadcast media ad avoidance in different media', Journal of Advertising, Vol. 26, No. 3, pp.61-76.

Taylor, D.G., Lewin, J.E.,and Strutton, D. (2011) 'Friends, fans and followers: do ads work on social networks? How gender and age shape receptivity', Journal of Advertising Research, Vol. 51, No. 1, pp.258-275.

Tuten, T.L. (2008) Advertising 2.0: Social Media Marketing in a Web 2.0 World, Praeger, London.

Vries, L., Gensler, S. and Leeflang, P.S.H. (2012) 'Popularity of brand posts on brand fan pages: an investigation of the effects of social media marketing', Journal of Interactive Marketing, Vol. 26, No. 2, pp.83-91.

Wang, C., Zhang, P., Choi, R. and Eredita, M.D. (2002) 'Understanding consumers attitude toward advertising', Eighth Americas Conference on Information Systems, pp.1143-1148.

Wang, K.Y., Ting, I.H. and Wu, H.J. (2013) 'Discovering interest groups for marketing in virtual communities: an integrated approach', Journal of Business Research, Vol. 66, No. 9, pp.1360-1366.

Wang, Y. and Sun, S. (2010) 'Assessing beliefs, attitudes and behavioral responses toward online advertising in three countries', International Business Review, Vol. 19, No. 4, pp.333-344.

Wolin, L.D. and Korgaonkar, P. (2003) 'Web advertising: gender differences in beliefs, attitudes and behavior', Internet Research, Vol. 13, No. 5, pp.375-385.

Wolin, L.D., Korgaonkar, P. and Lund, D. (2002) 'Beliefs, attitudes and behaviour towards web advertising', International Journal of Advertising, Vol. 21, No. 1, pp.87-113.

Yaakop, A., Anuar, M.M. and Omar, K. (2013) 'Like it or not: issue of credibility in Facebook advertising', Asian Social Science, Vol. 9, No. 3, pp.154-163.

Yadav, M.S. and Varadajan, R. (2005) 'Interactivity in the electronic marketplace: an exposition of the concept and implications for research', Journal of the Academy of Marketing Science, Vol. 33, No. 4, pp.585-603.

Yang, K.C.C. (2003) 'Internet users' attitudes toward and beliefs about internet advertising: an exploratory research from Taiwan', Journal of International Consumer Marketing, Vol. 15, No. 4, pp.43-65.

Zeng, F., Huang, L. and Dou, W. (2010) 'Social factors in user perceptions and responses to advertising in online social networking communities', Journal of Interactive Advertising, Vol. 10, No. 1, pp.1-14.

Zhou, Z. (2002) 'Users' attitudes toward web advertising: effects of internet motivation and Internet ability', Advances in Consumer Research, Vol. 29, No. 1, pp.71-78. 